\title{
Ultrasound-Stimulated Microbubbles Enhance Radiosensitization of Nasopharyngeal Carcinoma
}

\author{
Han Deng ${ }^{a, b}$ Yanxia Caic ${ }^{c}$ Qian Feng $^{d}$ Xiaoyan Wang ${ }^{c}$ Wenhong Tian ${ }^{c}$ \\ Shifeng Qiu ${ }^{d}$ Yuegang Wang ${ }^{d}$ Zhiliang Li $^{\mathrm{a}}$ Juefei Wu ${ }^{\mathrm{d}}$ \\ aDepartment of Cardiology, Zhujiang Hospital Southern Medical University, Guangzhou, 'bepartment \\ of Cardiology, Shenzhen Hospital, Southern Medical University, Shenzhen, 'Department of Hematology, \\ The eighth Affiliated Hospital, Sun Yat-sen University, Shenzhen, dDepartment of Cardiology, Nanfang \\ Hospital Southern Medical University, Guangzhou, China
}

\section{Key Words}

Ultrasound-stimulated microbubble $\cdot$ Radiosensitizer • Nasopharyngeal carcinoma • ANG II - AT1R

\begin{abstract}
Background/Aims: Recent studies indicate that therapies targeting the vasculature can significantly sensitize tumors to radiation. Ultrasound-stimulated microbubbles (USMBs) are regarded as a promising radiosensitizer. In this study, we investigated the effect of USMBs on the sensitivity of nasopharyngeal carcinoma (NPC) to radiation. Methods: Human NPC (CNE2) cells and human umbilical vein endothelial cells (HUVECs) were exposed to radiation $(0,2$, and $8 \mathrm{~Gy}$ ) alone or in combination with USMBs. Cell viability and apoptosis were measured with the MTT assay and flow cytometry, respectively. The angiogenic activity of HUVECs was detected using matrigel tubule formation. The in vitro effects induced by these treatments were confirmed in vivo with xenograft models of CNE-2 cells in nude mice by examining vascular integrity using color Doppler flow imaging and cell survival using immunohistochemistry. Additionally, the in vivo and in vitro expressions of angiotensin II (ANG II) and its receptor (AT1R) were detected by immunohistochemistry and western blotting, respectively. With CNE2 cells and HUVECs transfected with control, ANG II, or AT1R, perindopril (an inhibitor of angiotensin-converting enzyme) and candesartan (an inhibitor of AT1R) were used to verify the role of ANG II and AT1R in the radiosensitivity of tumor and endothelial cells by USMBs, by determining cell viability and apoptosis and angiogenic activity. Results: In the NPC xenografts, USMBs slightly reduced blood flow and CD34 expression, increased tumor cell death and ANG II and AT1R expression, and significantly enhanced the effects of radiation. With CNE-2 cells and HUVECs, the USMBs further enhanced the inhibition of tumor cell viability and endothelial tubule formation and further enhanced the increase in ANG II and AT1R due to radiation. Furthermore, perindopril and candesartan significantly enhanced the H. Deng, Y. Cai and Q. Feng contributed equally to this work.

\begin{tabular}{ll}
\hline Yuegang Wang, & Department of Cardiology, Nanfang Hospital Southern Medical University, Guangzhou, Guangdong; \\
Zhiliang Li & Department of Cardiology, Zhujiang Hospital Southern Medical University, Guangzhou, Guangdong (China) \\
and Juefei Wu & E-Mail yuegangw@hotmail.com; lizhiliang020@126.com; jaffiwu@hotmail.com
\end{tabular}
\end{abstract}




\section{Cellular Physiology Cell Physiol Biochem 2018;48:1530-1542 \\ \begin{tabular}{c|c|c|c|} 
DOI: 10.1159/000492263 & $\begin{array}{l}\text { O 2018 The Author(s). Published by S. Karger AG, Basel } \\
\text { www.karger.com/cpb }\end{array}$
\end{tabular} \\ Deng et al.: Microbubble Enhanced the Radiosensitization of Nasopharyngeal \\ Carcinoma}

inhibitory effect of radiation and USMBs on tumor cell growth and angiogenesis in vitro. Conclusions: We have demonstrated for the first time that USMB exposure can significantly enhance the destructive effect on NPC of radiation, and this effect might be further increased by ANG II and AT1R inhibition. Our findings suggest that USMBs can be used as a promising sensitizer of radiotherapy to treat NPC, and the clinical effect might be increased by ANG II and AT1R inhibition.

\section{Introduction}

Nasopharyngeal carcinoma (NPC) is a type of head and neck malignant neoplasm with poor differentiation that is highly metastatic. In 2008, more than 84,000 new cases of NPC were diagnosed worldwide and more than $50 \%$ of these cases died [1]. NPC occurs worldwide, but is geographically distributed to a higher extent within Southern China and Southeast Asia [2]. NPC derives from epithelial cells in the nasopharynx and can be classified into keratinizing squamous cell carcinoma, nonkeratinizing carcinoma, and undifferentiated carcinoma. The causes of NPC include genetic, viral, and dietary factors and their combinations [3].

With many types of therapies for cancers, radiation remains the leading treatment for most NPC patients because of the unique anatomical location and moderate radiosensitivity of the tumor. In addition to the primary cell death induced by damaging cell DNA, destruction of the vasculature as a result of endothelial cell apoptosis leads to secondary large-scale tumor killing [4]. As blood vessels are critical for tumors, angiogenesis is promoted during tumor progression to ensure an abundant blood supply. Growing evidence indicates that death of the tumor-feeding vasculature is an important contributor to tumor killing and a primary determinant of overall response to radiotherapy [5, 6]. However, radiotherapy often fails in NPC, especially for advanced-stage tumors [7], because resistance can be developed by tumors after radiotherapy. This can be achieved by enhancing DNA repair of cells and angiogenesis [8].

The renin-angiotensin system (RAS) plays an important role in radiotherapy resistance. It is involved in various biophysiological processes, including blood pressure control, tissue remodeling, and angiogenesis. It was found that the dysregulation of RAS activity played an important role in modulating tumor biology, and this correlated with poor prognosis [9]. Angiotensin II (Ang II), a biologically active peptide, has a central role in the RAS. The biologic activity of Ang II is generated by binding to its receptors, type 1 (AT1R) and type 2 (AT2R). However, most of its functions, including radioresistance, are mediated by AT1R [10]. Retrospective studies with hypertensive patients indicated that angiotensin-converting enzyme inhibitors (ACEIs and AT1R blockers (ARBs) decreased the risk of developing some types of cancers $[11,12]$. Furthermore, inhibition of tumor growth, angiogenesis, and metastasis by both ACEIs and ARBs was observed in mouse in vivo models $[13,14]$.

To overcome radioresistance and increase survival, many attempts have been made to develop new radiosensitizers [15-18]. Recent studies revealed that ultrasound-stimulated microbubbles (USMBs) induced vessel destruction in tumors [19-21]. Compared with antiangiogenic drugs, the microbubble provides ultrasound-guided local treatment to increase the probability of normal tissue sparing during treatment [22]. Recently, microbubbles have been used in cancer-treatment applications. It has been shown that the growth of colon cancer in mice was effectively inhibited by USMBs, which was achieved by blood vessel disruption and tumor tissue damage [23]. Based on the susceptibility of endothelial cells to microbubbles, it was confirmed that USMBs can significantly enhance the radiosensitivity of a variety of tumors, such prostate, bladder, and breast cancers [5, 24, 25].

Microbubbles are gas-filled microspheres coated with lipid, protein, or biopolymer. They are frequently used in medical ultrasound applications, such as imaging, gene delivery, tumor ablation, and medical disruption. They have a median diameter of about $3 \mu \mathrm{m}$, so can circulate within the blood after peripheral intravenous injection [23]. When exposed 


\section{Cellular Physiology Cell Physiol Biochem 2018;48:1530-1542 \begin{tabular}{l|l} 
DOI: 10.1159/000492263 & Ond Biochemistry \\
Published online: July 31, 2018 & $\begin{array}{l}\text { 2018 The Author(s). Published by S. Karger AG, Basel } \\
\text { www.karger.com/cpb }\end{array}$
\end{tabular} \\ Deng et al.: Microbubble Enhanced the Radiosensitization of Nasopharyngeal \\ Carcinoma}

to an appropriate ultrasound field, the encapsulating shell cracks, the encapsulated gas is released, and nonencapsulated bubbles are formed. This process is followed by the release of energy in various forms, such as thermal and shock waves, which mechanically perturb the surrounding tissue [25].

In this study, USMBs were employed as an adjuvant to radiation. Using mouse NPC tumor models together with high-resolution power Doppler ultrasound, we found that USMBs significantly sensitized the vasculature to radiation, which resulted in endothelial cell death and subsequently tumor cell death. Based on the observation that ANG II and AT1R expression levels were significantly increased after treatment with USMBs or in combination with radiation, we demonstrated in this study, using an ACEI and an ARB, that ANG II and AT1R inhibition further induced cell growth inhibition and cell apoptosis by radiation in combination with USMBs. Thus, we provided evidence that concomitant treatment with USMBs alone or in combination with ANG II or AT1R inhibitors might significantly increase the efficacy of radiation treatment for NPC.

\section{Materials and Methods}

\section{Cell culture and transfection}

Human nasopharyngeal carcinoma cells (CNE-2) and human umbilical vein endothelial cells (HUVECs) were used in this study. The cell lines were obtained from American Type Culture Collection (Manassas, VA, USA), and were maintained in Dulbecco's modified Eagle's medium (DMEM; Gibco, Carlsbad, CA, USA) supplemented with $10 \%$ fetal bovine serum (Gibco) and $100 \mathrm{U} / \mathrm{mL}$ penicillin/streptomycin at $37^{\circ} \mathrm{C}$ in a humid atmosphere containing $5 \% \mathrm{CO}_{2}$. The cells were cultured to $80 \%$ confluence and harvested using $0.25 \%$ trypsin-ethylenediamine tetraacetic acid (EDTA) solution (Sigma-Aldrich, St. Louis, MO, USA) at room temperature. The plenti6/V5-DEST vector (Invitrogen, Carlsbad, CA, USA) was used to harbor ANG II or AT1R cDNA through cloning of cDNA sequences into the BamH I and Asc I sites. After amplification and DNA sequence confirmation, CNE-2 cells and HUVECs were stably transfected with the ANG II, AT1R, or control vector using Lipofectamine 2000 and grown in DMEM containing blasticidin.

\section{Animals and tumor model}

Female 4-week-old nude mice weighing $16 \pm 1 \mathrm{~g}$ were purchased from Guangdong Experimental Animal Center (Foshan, China). They were housed in an animal facility at $24 \pm 2{ }^{\circ} \mathrm{C}$ with a relative humidity of $55+15 \%$, with free access to food and water. After more than 1 week for acclimatization to the experimental conditions, mice were inoculated with $1 \times 10^{6} \mathrm{CNE}-2$ cells suspended in $100 \mu \mathrm{L}$ matrigel into the lower right hind leg. Tumor formation in the mice was monitored twice weekly until a diameter of 5-8 mm was reached for experiments. All animal studies were conducted in accordance with the guidance of the Institutional Animal Care and Use Committee at Nanfang Hospital.

\section{Microbubble preparation}

We prepared the microbubbles according to the following method. In brief, microbubbles were composed of dipalmitoyl-phosphatidylcholine (Avanti Polar Lipids, Alabaster, AL, USA), dipalmitoyl phosphate (Avanti Polar Lipids), dipalmitoyl phosphoethanolamine glycol-5000 (Shearwater Polymers, Huntsville, AL, USA), glycerol, and propylene glycol dissolved in distilled water at an appropriate ratio. Next, perfluoropropane was infused into the solution, and the solution was shaken until a milky white color was formed. After being allowed to stand, the lower clear liquid was discarded and the microbubble solution was obtained (at a concentration of about $2.99 \times 10^{9}$ bubbles/ $\mathrm{mL}$ with a diameter of about $2.5 \mu \mathrm{m}$ ).

\section{In vivo treatment}

The tumor-bearing animals were divided into six groups ( $\mathrm{n}=8$ per group) and received one of the following treatments: radiation alone $(0,2$, or $8 \mathrm{~Gy})$ and a combination treatment of USMBs followed by radiation. The experiments were performed as previously described $[23,26]$. The microbubbles were injected into the tail vein at a concentration of $3 \%(\mathrm{v} / \mathrm{v}$, according to the total mouse blood volume). The lower bodies of the mice were immersed into a water bath at $37^{\circ} \mathrm{C}$ for ultrasound exposure. Tumors were 


\section{Cellular Physiology Cell Physiol Biochem 2018;48:1530-1542 \begin{tabular}{c|c|c|} 
DOI: 10.1159/000492263 & $\begin{array}{l}\text { O 2018 The Author(s). Published by S. Karger AG, Basel } \\
\text { www.karger.com/cpb }\end{array}$
\end{tabular} \\ Deng et al.: Microbubble Enhanced the Radiosensitization of Nasopharyngeal \\ Carcinoma}

exposed within the half maximum peak of the acoustic signal (focused at $8.5 \mathrm{~cm}$ with $26 \mathrm{~dB}$ beam width at focal point of $3.1 \mathrm{~cm}$ ) using a 16-cycle tone burst at a $238 \mathrm{-kHz}$ central frequency with an ultrasound transducer (IL0509HP, Valpey Fisher Inc., Hopkinton, MA, USA). With $570 \mathrm{kPa}$ peak negative pressure corresponding to a mechanical index of 0.8 , a $3-\mathrm{kHz}$ pulse repetition frequency for $50 \mathrm{~ms}$ was used. An intermittent $1950-\mathrm{ms}$ period between sonification was used. The total tumor insonification time was 750 ms over $5 \mathrm{~min}$. Next, $6 \mathrm{~h}$ after ultrasound treatment, tumors received a single dose of 0 , 2, or $8 \mathrm{~Gy}$ at a rate of $200 \mathrm{cGy} / \mathrm{min}$.

\section{In vivo imaging}

As previously described, blood flow was detected using color Doppler flow imaging by an Acuson Sequoia 512 system (Siemens, Mountain View, CA, USA) equipped with a 14L8 transducer. According to microbubble-specific contrast pulse sequencing technology, microvessel blood flow was detected with a low mechanical index of 0.08 .

\section{In vitro treatment}

CNE-2 cells received one of the following four treatments: (1) no treatment (control); (2) radiation alone (2 and 8 Gy); (3) USMBs alone; or (4) radiation plus USMBs. Further experiments were conducted with the transfected CNE-2 cells receiving one of the following three treatments: (1) radiation alone; (2) radiation plus USMB; or (3) a triple combination of ACEI/ARB, radiation, and USMB. About $8 \times 10^{5}$ cells were seeded in a $25-\mathrm{cm}^{2}$ flask approximately 1 day before ultrasound exposure. After adding $3 \%(\mathrm{v} / \mathrm{v})$ microbubbles, cells immediately received ultrasound or sham treatment and were incubated for $24 \mathrm{~h}$. Subsequently, cells were irradiated with a single dose of 2 or 8 Gy. For the triple treatment, ACEI/ARB was received at the same time as the microbbubles. Following these treatments, cells were used for western blotting and cell viability assays as described below.

\section{Western blotting}

Proteins were extracted from the tumor tissues and cells by lysing with RIPA buffer. Loading buffer with $20 \mu \mathrm{g}$ cell protein or $50 \mu \mathrm{g}$ tissue protein was used for sodium dodecyl sulfate-polyacrylamide gel electrophoresis (SDS-PAGE). After separation by SDS-PAGE, the proteins were transferred onto a nitrocellulose membrane and incubated with 5\% nonfat milk in Tris-buffered saline +Tween 20 for about $1 \mathrm{~h}$ at room temperature. Then, protein bands were incubated with antibodies against ANG II, AT1R, and GAPDH (Sigma-Aldrich) at $4^{\circ} \mathrm{C}$ overnight. After washing 3 times with phosphate-buffered saline (PBS) + Tween 20 , the samples were incubated with horseradish peroxidase-conjugated secondary antibody at room temperature for $1 \mathrm{~h}$. Following the last washing, immunoreactive binding was detected with an electrochemiluminescence detection kit (Amersham, GE Healthcare, Little Chalfont, UK). GAPDH was used as the internal reference.

\section{Cell viability}

Cell proliferation was measured with the 3-(4, 5-dimethyl-2-thiazolyl)-2, 5-diphenyl-2-H- tetrazolium bromide (MTT) assay (KeyGen, Nanjing, China). In brief, $2 \times 10^{3}$ CNE-2 cells were seeded in 96-well plates and grown in complete medium. At $24 \mathrm{~h}, 48 \mathrm{~h}$, and $72 \mathrm{~h}$ after incubation, the medium was replaced with serum-free medium and MTT was added. After incubation for $4 \mathrm{~h}$ at $37^{\circ} \mathrm{C}$, the medium containing MTT was removed and replaced with $150 \mu \mathrm{L}$ DMSO. Then, the plates were gently rotated on a shaker for $10 \mathrm{~min}$ to completely dissolve the precipitate. Absorbance was measured at $490 \mathrm{~nm}$ using a microplate reader (BioRad, Hercules, CA, USA).

\section{Flow cytometry}

The cells for apoptosis analysis were detached with $0.25 \%$ EDTA-free trypsin and collected in centrifuge tubes. After centrifugation at $1000 \mathrm{rpm}$ for $5 \mathrm{~min}$, the medium was discarded and the cells were resuspended in pre-cooled PBS. Subsequently, cells were fixed in pre-cooled $70 \%$ ethanol and placed at $4{ }^{\circ} \mathrm{C}$ overnight. After washing twice with PBS, the cells were stained with propidium iodide (KeyGen) for $30 \mathrm{~min}$ at $4^{\circ} \mathrm{C}$ in the dark. Data were collected using a BD FACSCalibur flow cytometer (BD Biosciences, Franklin Lakes, NJ, USA).

\section{KARGER}




\section{Cellular Physiology Cell Physiol Biochem 2018;48:1530-1542 and Biochemistry Published online: July 31, $2018 \quad \begin{aligned} & \text { DOI: 10.1159/000492263 } 2018 \text { The Author(s). Published by S. Karger AG, Basel } \\ & \text { www.karger.com/cpb }\end{aligned}$ \\ Deng et al.: Microbubble Enhanced the Radiosensitization of Nasopharyngeal \\ Carcinoma}

\section{Endothelial tube forming assay (in vitro angiogenesis)}

Endothelial function was assessed by matrigel tubule formation assay as previously described [26]. About $2 \times 10^{6} / \mathrm{mL}$ HUVECs received the same treatments as the CNE- 2 cells. Combined treatments were performed by exposure to USMBs followed by irradiation within $2 \mathrm{~min}$. The cells from each group were added in triplicate to the 96-well tissue culture plate coated with matrigel (Cell Biolabs, San Diego, CA, USA) and were incubated at $37^{\circ} \mathrm{C}$ with ACEI or ANG II inhibitor for about $18 \mathrm{~h}$. The growth medium was gently removed, and formed tubular structures were evaluated.

\section{Histopathology, immunohistochemistry, and TUNEL staining}

After fixing in $10 \%$ neutral buffered formalin, the tumor tissues were spliced and partly dehydrated with ethanol and embedded in paraffin wax. Sections (5 $\mu \mathrm{m}$ thick) were prepared, dewaxed, and hydrated. Some of the samples were stained using hematoxylin and eosin (H\&E) for histopathological evaluation.

Some of the sections were used for immunohistochemistry. In brief, samples were incubated at room temperature with $3 \%$ hydrogen peroxide for $5 \mathrm{~min}$ to block endogenous peroxidase, and then with normal goat serum for $30 \mathrm{~min}$ to reduce nonspecific binding. Then, the samples were incubated with anti-ANG II antibody and anti-AT1R antibody (abcam, Cambridge, UK) at $4^{\circ} \mathrm{C}$ overnight. Following incubation with biotinylated secondary antibody, the peroxidase reaction was developed with the DAB kit (Maixin Bio, Fuzhou, China). Finally, hematoxylin was used to counterstain nuclei. For a negative control, nonimmune serum was applied as the primary antibody.

In order to detect cell death, the terminal deoxynucleotidyl transferase dUTP nick end labeling (TUNEL) assay was performed with a commercial kit (DeadEnd Colorimetric TUNEL System, Promega, Mannheim, Germany) using the peroxidase-inactivated sections, according to the manufacturer's protocol.

\section{Statistical analysis}

All data were analyzed with SPSS 21.0 (SPSS, Chicago, IL, USA). Data are expressed as the mean \pm standard error of the mean. Data between two groups were compared using Student's t-test, and data within groups were tested using one-way analysis of variance. $\mathrm{P}<0.05$ was considered statistically significant.

\section{Results}

\section{USMBs sensitized tumor cells and endothelial cells to radiation in vitro}

To observe the effect of USMBs on the sensitivity of tumor cells to radiation, CNE- 2 cells received the designated treatment and cell viability was examined at various timepoints. Firstly, we confirmed that treatment with USMBs or radiation alone significantly decreased the viability of the cells (Fig. 1A). The inhibitory effect by radiation was increased in a timeand dose-dependent manner. Secondly, cell growth inhibition by radiation was enhanced by the USMBs. Based on these findings, apoptosis was examined by flow cytometry at $24 \mathrm{~h}$ after treatment. Consistent with the above results, apoptosis was significantly increased by either radiation or USMB treatment (Fig. 1B and 1C). Furthermore, a synergetic effect on cell apoptosis of the two treatments was observed. All these results indicated that USMBs can induce cell growth inhibition and sensitize cells to radiation.

The effect of USMBs on endothelial cell function was assessed by matrigel tubule formation in vitro. Consistent with the observations for CNE- 2 cells, angiogenic potential, as evidenced by decreased nodes and tubes, was inhibited by either radiation or USMB in comparison with the control (Fig. 1D). Additionally, inhibition by radiation alone was doserelevant and was further enhanced by USMB treatment. These results confirmed that USMBs can directly inhibit the function of endothelial cells; the effects of radiation and USMBs were synergistic. Thus, treatment with USMBs might promote the destructive role of radiation in the vascular system.

USMBs sensitized tumor vasculature to radiotherapy

In order to confirm the effect of USMB treatment on the vasculature by radiotherapy in vivo, CNE-2 NPC cells were exposed to different levels of ionizing radiation with or without 


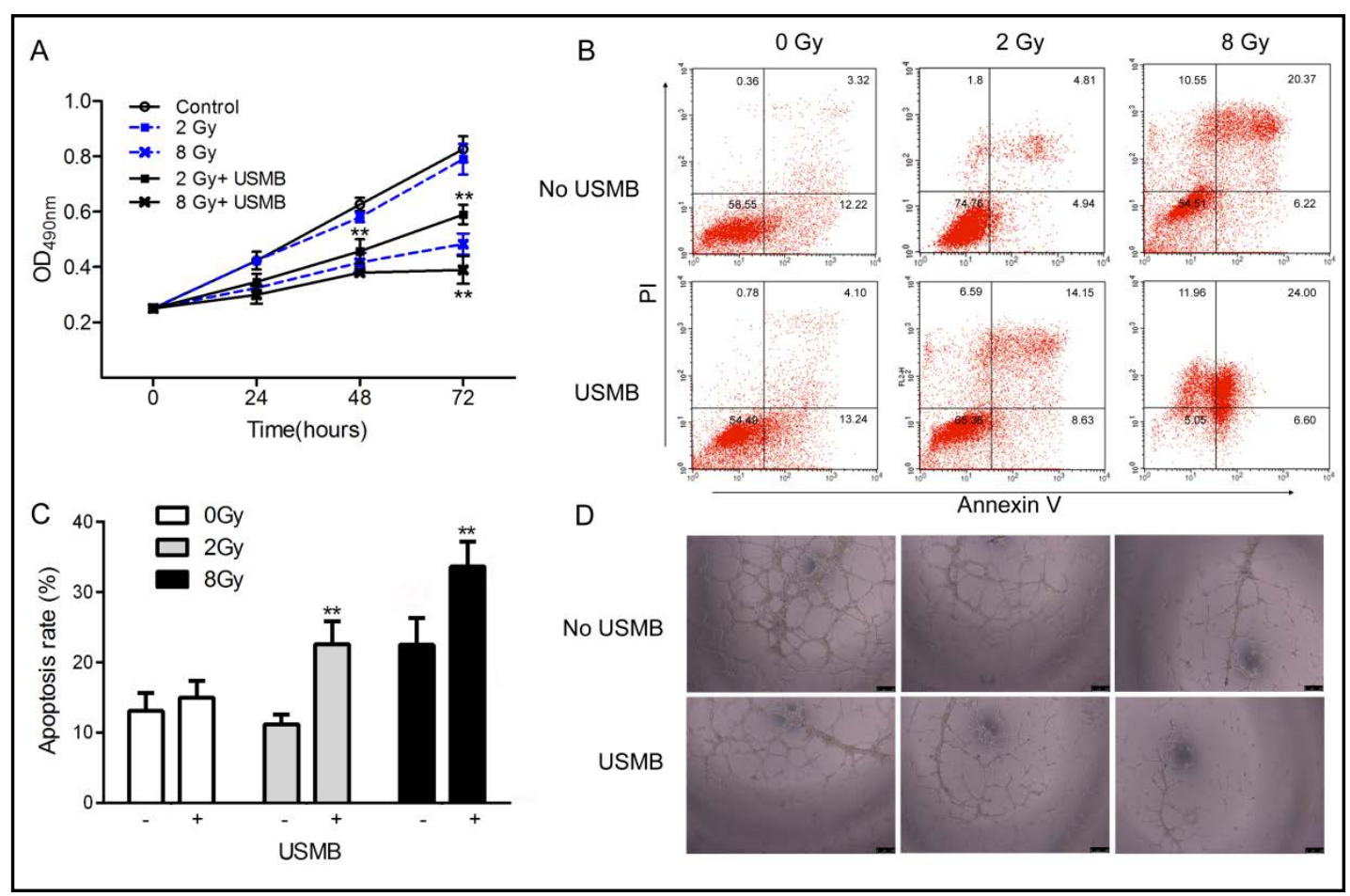

Fig. 1. Ultrasound-stimulated microbubbles (USMBs) sensitized CNE-2 cells and human umbilical vein endothelial cells (HUVECs) to radiation. (A) The viability of CNE-2 cells was detected by MTT assay at $24 \mathrm{~h}, 48 \mathrm{~h}$, and $72 \mathrm{~h}$ after treatment. Tests were performed in triplicate. (B, C) Apoptosis of CNE-2 cells was determined by flow cytometry at $24 \mathrm{~h}$ after treatment. (D) Representative images of matrigel tubule formation with HUVECs at $18 \mathrm{~h}$ after treatment; magnification $\times 10 .{ }^{* *} \mathrm{P}<0.01$ vs. radiation treatment at the same timepoint and dose.

USMB treatment. As shown in Fig. 2A, radiation significantly decreased blood flow dose dependently. Additionally, we observed that USMB treatment alone slightly decreased blood flow in tumors. Furthermore, the synergistic effect of USMBs was observed on the inhibitory role of radiation on blood flow at each dose. All these findings indicated that carcinoma microvessels were responsive to treatment with radiation and USMB, and the response to these treatments was synergistic.

To explore whether this reduction in blood flow was induced by a change in the morphology of the vasculature, the endothelial marker cluster of differentiation 34 (CD34) was detected by immunohistochemistry. As shown in Fig. 2B, both radiation and USMB reduced CD34 expression. The combination treatment further reduced the expression of CD34, indicating that USMBs promoted the reduced CD34 expression by radiation. As a marker of endothelial cells, the expression of CD34 was equivalent to the presence of endothelial cells, and was used to determine the structure of the vasculature. Analysis of CD34 expression revealed that the vessel numbers were significantly reduced after treatment with radiation or USMBs, and further reduced by their combined treatment. This indicated that the blood flow reduction resulted from endothelial damage and the consequent vessel lesion caused by radiation and enhanced by USMBs.

\section{USMBs sensitized tumor cells to radiation in vivo}

To observe whether the decrease in blood flow is correlated with tumor damage, tumor cell death was assessed by histopathology and TUNEL assay. As shown in Fig. 3A, treatment with radiation significantly induced tumor cell death, and this was most apparent at the highest dose (8 Gy). We observed that USMBs significantly induced cell death, and this significantly enhanced the damaging effect of radiation. Furthermore, there was apparent 


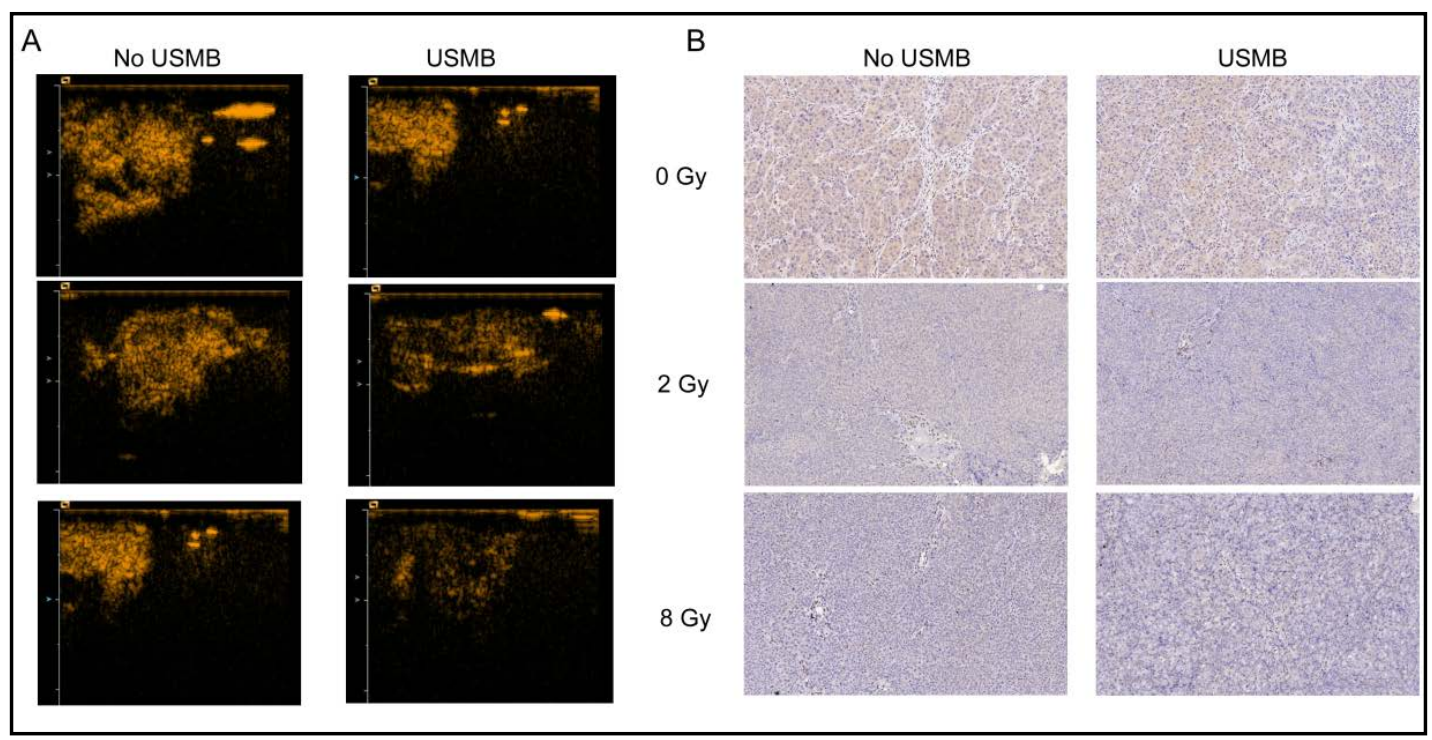

Fig. 2. USMBs sensitized the vasculature in tumors to radiation. (A) Monitoring blood flow in tumors with power Doppler ultrasound after treatment with radiation alone or in combination with microbubbles. (B) CD34, an endothelial marker, was determined by immunohistochemistry. Magnification $\times 10$.

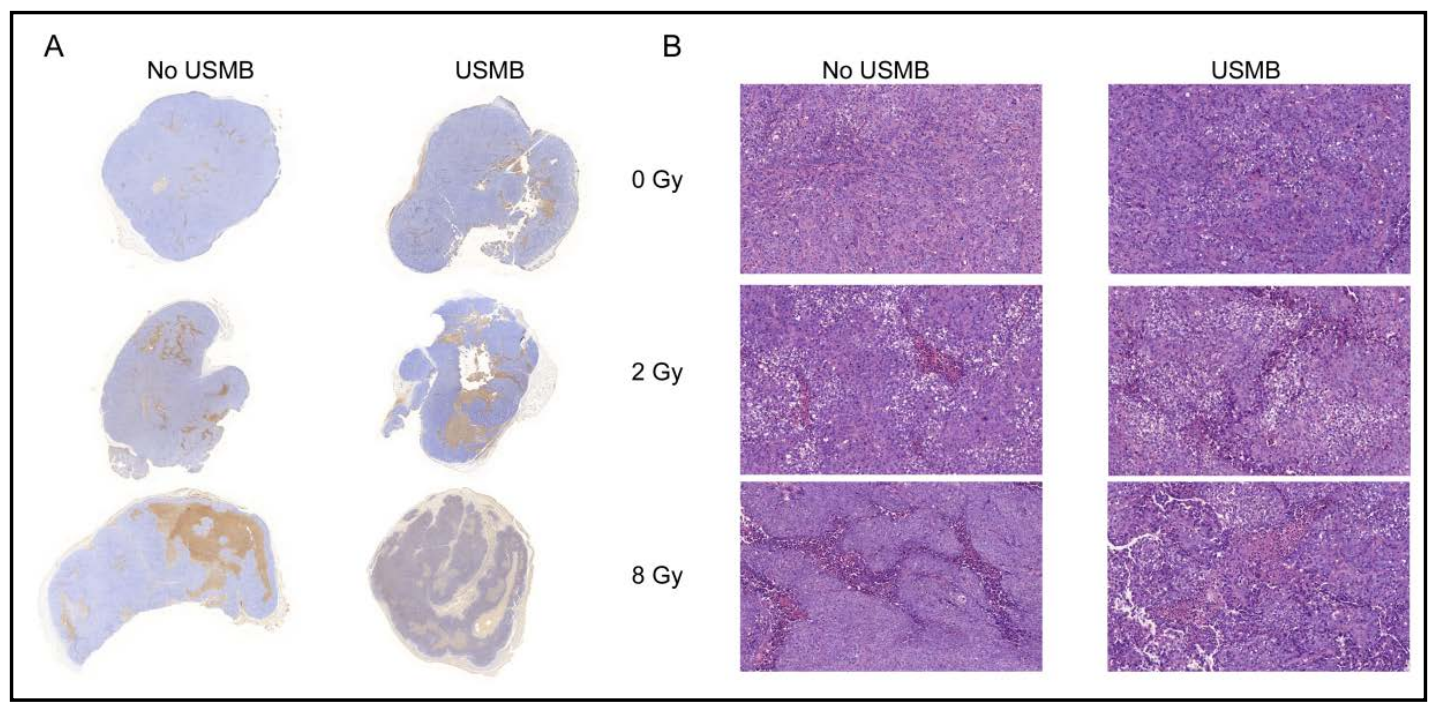

Fig. 3. USMBs sensitized the vasculature in tumor cells to radiation. TdT-mediated dUTP-biotin nick endlabeling (TUNEL) staining (A) and H\&E(B) were performed $24 \mathrm{~h}$ after treatment. The results show that tumor necrosis was induced dose dependently by radiation, and this was significantly enhanced by USMBs. Magnification $\times 1$ for TUNEL assay and $\times 10$ for histopathology.

damage within the central region of the tumor, whereas less significant signs of cell death were observed within circumferential tumor regions. H\&E staining confirmed these results (Fig. 3B). Additionally, vessel damage was observed in the center, indicating that tumor cell death might occur around the blood vessels.

\section{Effect of radiation and USMBs on the expression of ANGII and AT1R}

Next, we investigated the expression of ANG II and AT1R in xenograft tumors. As shown in Fig. 4A, ANG II and AT1R were detectable in the xenograft tumors and their immunoreactivities were mainly observed in the cytoplasm and extracellular matrix of tumor cells. After radiation treatment, their expressions were increased in a dose-dependent 
Deng et al.: Microbubble Enhanced the Radiosensitization of Nasopharyngeal

Carcinoma

manner and were further increased by USMB treatment. These findings indicate that USMBs significantly enhanced the pro-expression effect on ANG II and AT1R of radiation exposure.

Tumors comprise malignant cells, endothelial cells, immune cells, and others, and all these cells are associated with tumor pathogenesis and development. To observe whether radiation and USMBs affect the malignant cell directly, generation of ANG II and AT1R was measured by western blotting in CNE-2 cells and HUVECs. Consistent with the in vivo results, ANG II and AT1R were significantly increased after radiation treatment (Fig. 4B and 4C); these increases were further enhanced by USMB exposure. Together, our in vivo and in vitro results suggest that both radiation and USMBs can directly increase the expression of ANG II and AT1R in tumor and endothelial cells.

\section{Effect of AT1R and ANG II inhibition on the radiosensitization by USMB}

The RAS plays an important role in the hyperplasia and angiogenesis that underpin cell proliferation and malignancy. In this study, the effects of AT1R and ANG II on radiosensitization were investigated in transfected cells. Firstly, we examined the effects of the ACEI perindopril and the ARB candesartan on the growth of cells with control transfection. We found that perindopril and candesartan induced cytotoxicity in a dose-dependent manner without cell growth inhibition at maximal concentrations of $0.1 \mu \mathrm{M}$ and $1 \mu \mathrm{M}$, respectively (Fig. $5 \mathrm{~A}$ and 5B).

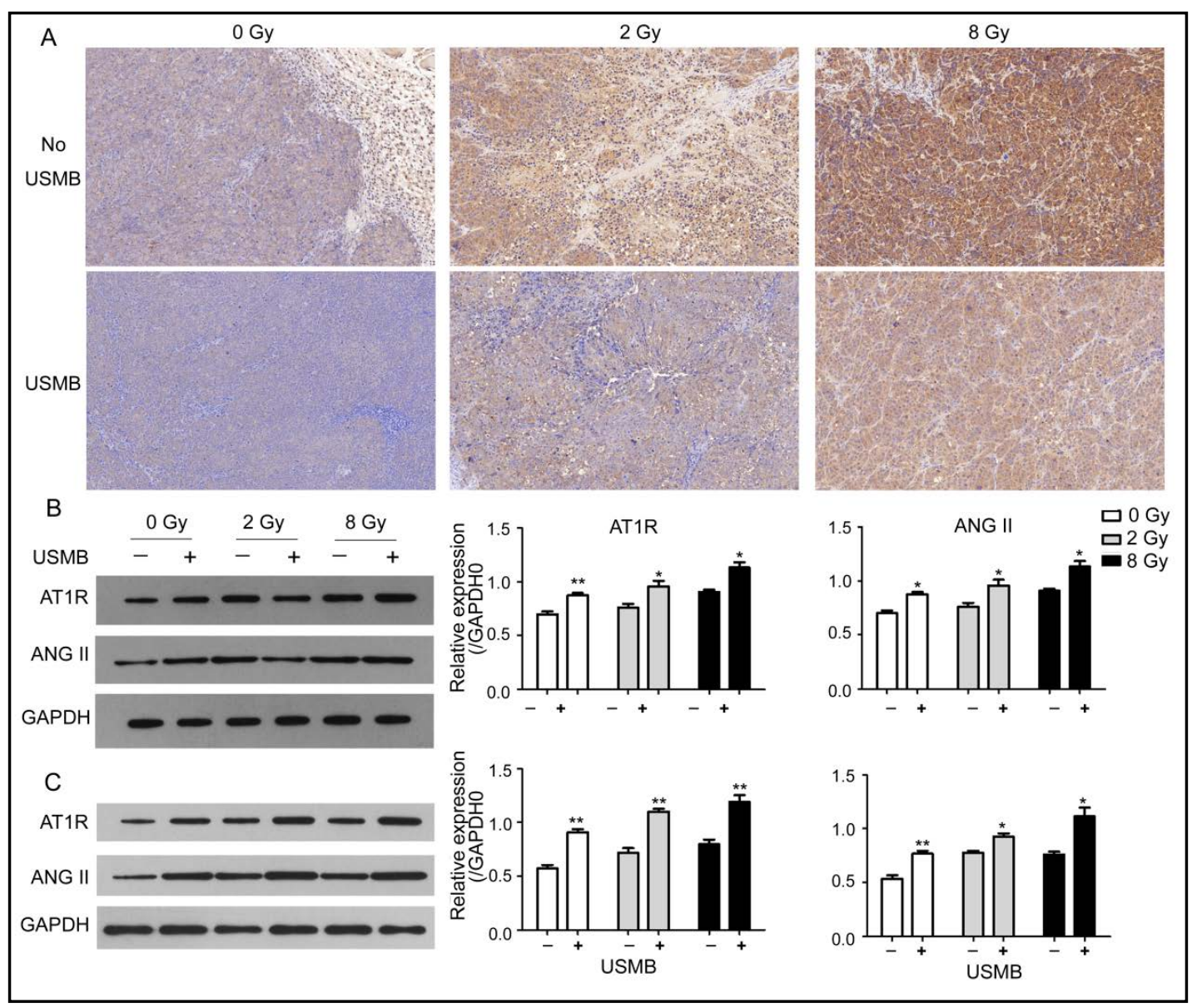

Fig. 4. Effect on AT1R and ANG II expression of radiation alone or in combination with USMBs., Expression levels in the xenograft tumors (A), CNE-2 cells (B), and HUVECs (C) were determined by immunohistochemistry and western blotting $24 \mathrm{~h}$ after treatment. ${ }^{* *} \mathrm{P}<0.01$ vs radiation treatment only at the same dose.

\section{KARGER}




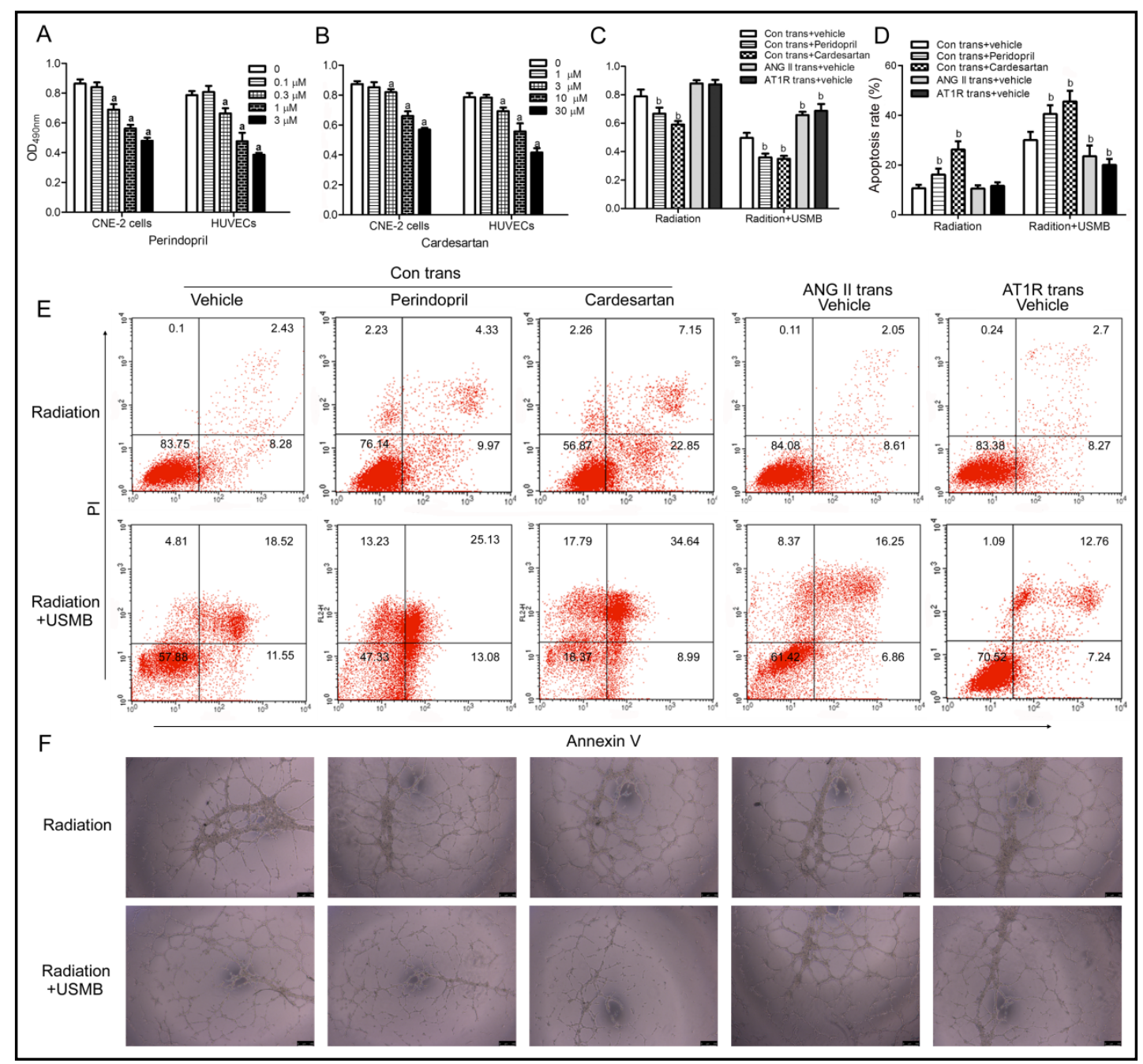

Fig. 5. Effect of perindopril and candesartan on tumor and endothelial cells. After exposure for $72 \mathrm{~h}$ to the angiotensin-converting enzyme inhibitor perindopril (A) or the AT1R inhibitor candesartan (B), growth of the cells transfected with control vector was determined. The cells with control transfection received $0.1 \mu \mathrm{M}$ perindopril, $1 \mu \mathrm{M}$ candesartan, or vehicle, while cells with ANG II or AT1R transfection received only control treatment. After treatment for $72 \mathrm{~h}$, the cells were used for viability determination (C) or apoptosis analysis (D, E). Additionally, tubule formation was examined following treatment (F). Magnification $\times 10$. ${ }^{a} \mathrm{P}<0.01 \mathrm{vs}$. the control in the same cells; ${ }^{b} \mathrm{P}<0.01$ vs the control cells. Con trans, control transfection; ANG II trans, ANG II transfection; AT1R trans, AT1R transfection.

To maximally reduce cytotoxicity, $0.1 \mu \mathrm{M}$ perindopril and $1 \mu \mathrm{M}$ candesartan were used in the following studies. The cell viability assay showed that cell growth inhibition by radiation alone or in combination with USMBs was significantly enhanced by the inhibitors, whereas inhibition was significantly blocked in the cells transfected with ANGII or AT1R (Fig. 5C). Next cell apoptosis was determined by flow cytometry and endothelial function was determined by the tubule formation assay. It was noted that both cell apoptosis and inhibition of tubule formation were significantly increased after treatment with perindopril or candesartan, but significantly suppressed after ANGII and AT1R overexpression (Fig. 5D$5 F$ ). This was consistent with the results of the cell viability assay described above.

Together, all our results indicate that both ANG II and AT1R inhibition significantly sensitized the tumor and endothelial cells to radiation alone or combined radiation with USMBs. 


\section{Cellular Physiology Cell Physiol Biochem 2018;48:1530-1542 \begin{tabular}{l|l} 
DOI: 10.1159/000492263 & $\begin{array}{l}\text { O } 2018 \text { The Author(s). Published by S. Karger AG, Basel } \\
\text { www.karger.com/cpb }\end{array}$
\end{tabular} \\ Deng et al.: Microbubble Enhanced the Radiosensitization of Nasopharyngeal \\ Carcinoma}

\section{Discussion}

In this study, we observed the effects on the NPC tumor model of USMBs and radiation using histopathology and high-frequency Doppler ultrasound. This was the first time that direct evidence has been provided to show that USMBs can enhance the response to radiation in a model of NPC. An ACEI and an AT1R antagonist were used to test whether the effect of radiation and USMBs can be further enhanced. The additive effect on radiation treatment or in combination with USMBs was observed in vitro.

Radiation is one of the most effective treatments for some types of cancer, such as NPC and brain tumor, due to its excellent local control and increased overall survival rates [27]. Consistent with the reported efficacy in NPC, tumor cell death was significantly induced by radiation in this study. Despite the wide use and well-recognized efficacy of radiotherapy, resistance to radiation can be acquired by the surviving cells. Following radiation-induced damage of cells in tumors, many survival pathways are activated to protect cells from death. These pathways not only directly promote cell survival by increasing proliferation, invasion, and anti-apoptosis, but also contribute to improve the microenvironment, such as through angiogenesis [28-31]. Similarly, NPC can acquire resistance to radiation through antiapoptotic pathways by increasing DNA damage repair and through facilitating angiogenesis by enhancing ANG II. In this study, we found that ANG II and AT1R were significantly increased in the tumor xenografts. ANG II has been shown to be pro-angiogenic through several potential mechanisms mainly via AT1R, including increasing expression of key growth factors, such as vascular endothelial growth factor (VEGF) and basic fibroblast growth factor, and increasing the production of matrix metalloproteinases to modulate new vessel formation [32].

To improve the efficacy of radiotherapy against tumors and overcome resistance, it is used in combination with cytotoxic drugs or cancer therapy targeting the vasculature. However, the use of cytotoxic drugs results in a range of adverse effects, commonly including hyperuricemia, bone marrow suppression, oral mucositis, gastrointestinal discomfort, and alopecia. Additionally, there are specific adverse effects associated with targeted cancer therapy, such as hematological and cardiovascular changes with VEGF antibody. With radiotherapy, a variable period of treatment with cytotoxic or targeting drugs is likely to induce resistance due to genetic heterogeneity and instability in tumors. With regard to local responses, it has been suggested that USMBs are an adjuvant therapy that can enhance the antitumor effectiveness of chemotherapy and radiotherapy. In this study, we observed that adjuvant USMB treatment had an additive effect on radiotherapy, which was demonstrated by a significant increase in tumor cell death and vascular destruction.

It is well recognized that the major mechanism by which USMBs induce cell death is associated with mechanical perturbation of the surrounding tissues and the dysregulated mediators of cell apoptosis. During microbubble oscillation and cavitation, the surrounding cells can be damaged and the adjacent microvessels can even become ruptured. Following these mechanical changes, a range of biological effects on surrounding cells can be induced at physiological and tissue levels due to released energy. These biological effects include gene expression changes, as well as cell death and vascular shutdown [5, 33]. Consistently, slightly increased vascular shutdown and tumor cell death were observed after USMB treatment in this study. Tumor cell death was linked to the biophysical damage of tumor endothelial cells due to USMB stimulation, subsequently leading to ceramide signaling and vascular shutdown due to endothelial cell death [34]. Additionally, tumor cell injury and lysis were directly induced by USMBs. This might be due to the extravasation of microbubbles into tumor tissues, based on the observations that microvessels ruptured on a microsecond time scale after oscillation resulting in the leakage of red blood cells [25].

The synergistic effect of USMBs on radiation therapy varies depending on the ultrasound frequency and the interval between USMB therapy and radiation treatment. The lower the ultrasonic frequency, the stronger the ultrasonic cavitation effect will be. A previous study 


\section{Cellular Physiology Cell Physiol Biochem 2018;48:1530-1542 \begin{tabular}{l|l} 
DOI: 10.1159/000492263 & Ond Biochemistry \\
Published online: July 31, 2018 & $\begin{array}{l}\text { 2018 The Author(s). Published by S. Karger AG, Basel } \\
\text { www.karger.com/cpb }\end{array}$
\end{tabular} \\ Deng et al.: Microbubble Enhanced the Radiosensitization of Nasopharyngeal \\ Carcinoma}

showed that an ultrasound frequency of $238 \mathrm{kHz}$ can efficiently hinder the growth of tumors [23]. Furthermore, it was suggested that treatment effects were optimal when USMBs and radiation were delivered within $6 \mathrm{~h}$ of each other [26]. Employing the above methods produced the expected results, although the microbubbles used in this study were prepared differently from those used in other studies; here, they were prepared with distilled water instead of PBS to dissolve phospholipids. The difference in biological effect induced by the various methods of production needs to be examined in further studies.

The resistance of tumors to therapy is associated with the level of ANG II. In this study, the protein and its receptor, AT1R, were significantly induced in vivo after USMB treatment, while USMBs significantly enhanced the effectiveness of radiotherapy. The expression of ANG II and AT1R can be significantly induced by hypoxia-inducible factor 1-alpha. Therefore, the vascular shutdown following endothelial cell damage and apoptosis might contribute importantly to the increased expression of ANG II and AT1R. Using CNE-2 cells, we confirmed for the first time that ANG II and AT1R in NPC cells are directly increased by radiation and USMBs. However, the underlying mechanisms need further investigation. Nevertheless, we observed that inhibiting AT1R and ANG II can significantly enhanced CNE-2 inhibition by radiation alone or in combination with USMBs.

\section{Conclusion}

USMBs are an attractive vascular targeting agent that can improve the effects of radiation on NPC tumors. This might be achieved by a synergistic effect on endothelial and tumor cell disruption. Radiotherapy fails in a considerable number of cases, and our results suggest that populations with radioresistance may have a higher sensitivity to radiation in combination with USMBs. Furthermore, our observations provide new insights into the clinical significance of using ANG II and AT1R inhibition together with radiation and USMBs.

\section{Acknowledgements}

This work was partially supported by the Guangdong Natural Science Funds for Distinguished Young Scholar (2016A030306028) and the Guangzhou Science and Technology Program (201506010021).

\section{Disclosure Statement}

The authors declare that there are no conflicts of interest regarding the publication of this paper.

\section{References}

-1 Jemal A, Bray F, Center MM, Ferlay J, Ward E, Forman D: Global cancer statistics. CA Cancer J Clin 2011;61:69-90.

-2 Chang ET, Adami HO: The enigmatic epidemiology of nasopharyngeal carcinoma. Cancer Epidemiol Biomarkers Prev 2006;15:1765-1777.

3 Wang T, Hu K, Ren J, Zhu Q, Wu G, Peng G: Polymorphism of VEGF-2578C/A associated with the risk and aggressiveness of nasopharyngeal carcinoma in a Chinese population. Mol Biol Rep 2010;37:59-65.

-4 Paris F, Fuks Z, Kang A, Capodieci P, Juan G, Ehleiter D, Haimovitz-Friedman A, Cordon-Cardo C, Kolesnick R: Endothelial apoptosis as the primary lesion initiating intestinal radiation damage in mice. Science 2001;293:293-297. 


\section{Cellular Physiology Cell Physiol Biochem 2018;48:1530-1542 and Biochemistry Published online: July 31, $2018 \quad \begin{aligned} & \text { DOI: 10.1159/000492263 } 2018 \text { The Author(s). Published by S. Karger AG, Basel } \\ & \text { www.karger.com/cpb }\end{aligned}$ \\ Deng et al.: Microbubble Enhanced the Radiosensitization of Nasopharyngeal \\ Carcinoma}

5 Czarnota GJ, Karshafian R, Burns PN, Wong S, Al Mahrouki A, Lee JW, Caissie A, Tran W, Kim C, Furukawa M, Wong E, Giles A: Tumor radiation response enhancement by acoustical stimulation of the vasculature. Proc Natl Acad Sci U S A 2012;109:E2033-2041.

6 Folkman J: Role of angiogenesis in tumor growth and metastasis. Semin Oncol 2002;29:15-18.

-7 Rottey S, Madani I, Deron P, Van Belle S: Modern treatment for nasopharyngeal carcinoma: current status and prospects. Curr Opin Oncol 2011;23:254-258.

8 Jameel JK, Rao VS, Cawkwell L, Drew PJ: Radioresistance in carcinoma of the breast. Breast 2004;13:452460.

-9 George AJ, Thomas WG, Hannan RD: The renin-angiotensin system and cancer: old dog, new tricks. Nat Rev Cancer 2010;10:745-759.

10 de Gasparo M, Catt KJ, Inagami T, Wright JW, Unger T: International union of pharmacology. XXIII. The angiotensin II receptors. Pharmacol Rev 2000;52:415-472.

$>11$ Lever AF, Hole DJ, Gillis CR, McCallum IR, McInnes GT, MacKinnon PL, Meredith PA, Murray LS, Reid JL, Robertson JW: Do inhibitors of angiotensin-I-converting enzyme protect against risk of cancer? Lancet 1998;352:179-184.

12 Christian JB, Lapane KL, Hume AL, Eaton CB, Weinstock MA, Trial V: Association of ACE inhibitors and angiotensin receptor blockers with keratinocyte cancer prevention in the randomized VATTC trial. J Natl Cancer Inst 2008;100:1223-1232.

13 Rodrigues-Ferreira S, Abdelkarim M, Dillenburg-Pilla P, Luissint AC, di-Tommaso A, Deshayes F, Pontes CL, Molina A, Cagnard N, Letourneur F, Morel M, Reis RI, Casarini DE, Terris B, Couraud PO, Costa-Neto CM, Di Benedetto M, Nahmias C: Angiotensin II facilitates breast cancer cell migration and metastasis. PLoS One 2012;7:e35667.

14 Deshayes F, Nahmias C: Angiotensin receptors: a new role in cancer? Trends Endocrinol Metab 2005;16:293-299.

15 Wang F, Tang J, Li P, Si S, Yu H, Yang X, Tao J, Lv Q, Gu M, Yang H, Wang Z: Chloroquine Enhances the Radiosensitivity of Bladder Cancer Cells by Inhibiting Autophagy and Activating Apoptosis. Cell Physiol Biochem 2018;45:54-66.

16 Jiang LP, Zhu ZT, Zhang Y, He CY: Downregulation of MicroRNA-330 Correlates with the Radiation Sensitivity and Prognosis of Patients with Brain Metastasis from Lung Cancer. Cell Physiol Biochem 2017;42:2220-2229.

17 Song Y, Zuo Y, Qian XL, Chen ZP, Wang SK, Song L, Peng LP: Inhibition of MicroRNA-21-5p Promotes the Radiation Sensitivity of Non-Small Cell Lung Cancer Through HMSH2. Cell Physiol Biochem 2017;43:12581272.

18 Zong Y, Feng S, Cheng J, Yu C, Lu G: Up-Regulated ATF4 Expression Increases Cell Sensitivity to Apoptosis in Response to Radiation. Cell Physiol Biochem 2017;41:784-794.

19 Wood AK, Ansaloni S, Ziemer LS, Lee WM, Feldman MD, Sehgal CM: The antivascular action of physiotherapy ultrasound on murine tumors. Ultrasound Med Biol 2005;31:1403-1410.

20 Wood AK, Schultz SM, Lee WM, Bunte RM, Sehgal CM: Antivascular ultrasound therapy extends survival of mice with implanted melanomas. Ultrasound Med Biol 2010;36:853-857.

-21 Wang J, Zhao Z, Shen S, Zhang C, Guo S, Lu Y, Chen Y, Liao W, Liao Y, Bin J: Selective depletion of tumor neovasculature by microbubble destruction with appropriate ultrasound pressure. Int J Cancer 2015;137:2478-2491.

-22 Ho YJ, Wang TC, Fan CH, Yeh CK: Current progress in antivascular tumor therapy. Drug Discov Today 2017;22:1503-1515.

23 Huang P, You X, Pan M, Li S, Zhang Y, Zhao Y, Wang M, Hong Y, Pu Z, Chen L, Yang G, Guo Y: A novel therapeutic strategy using ultrasound mediated microbubbles destruction to treat colon cancer in a mouse model. Cancer Lett 2013;335:183-190.

24 Tran WT, Iradji S, Sofroni E, Giles A, Eddy D, Czarnota GJ: Microbubble and ultrasound radioenhancement of bladder cancer. Br J Cancer 2012;107:469-476.

25 El Kaffas A, Czarnota GJ: Biomechanical effects of microbubbles: from radiosensitization to cell death. Future Oncol 2015;11:1093-1108.

-26 Al-Mahrouki AA, Wong E, Czarnota GJ: Ultrasound-stimulated microbubble enhancement of radiation treatments: endothelial cell function and mechanism. Oncoscience 2015;2:944-957. 


\section{Cellular Physiology Cell Physiol Biochem 2018:48:1530-1542 \begin{tabular}{l|l} 
DOI: 10.1159/000492263 & $\begin{array}{l}\text { O } 2018 \text { The Author(s). Published by S. Karger AG, Basel } \\
\text { www.karger.com/cpb }\end{array}$
\end{tabular}}

Deng et al.: Microbubble Enhanced the Radiosensitization of Nasopharyngeal

Carcinoma

27 Huang D, Bian G, Pan Y, Han X, Sun Y, Wang Y, Shen G, Cheng M, Fang X, Hu S: MiR-20a-5p promotes radioresistance by targeting Rab27B in nasopharyngeal cancer cells. Cancer Cell Int 2017;17:32.

28 Shimura T, Noma N, Oikawa T, Ochiai Y, Kakuda S, Kuwahara Y, Takai Y, Takahashi A, Fukumoto M: Activation of the AKT/cyclin D1/Cdk4 survival signaling pathway in radioresistant cancer stem cells. Oncogenesis 2012;1:e12.

29 Minjgee M, Toulany M, Kehlbach R, Giehl K, Rodemann HP: K-RAS(V12) induces autocrine production of EGFR ligands and mediates radioresistance through EGFR-dependent Akt signaling and activation of DNAPKcs. Int J Radiat Oncol Biol Phys 2011;81:1506-1514.

-30 Shimura T, Kakuda S, Ochiai Y, Nakagawa H, Kuwahara Y, Takai Y, Kobayashi J, Komatsu K, Fukumoto M: Acquired radioresistance of human tumor cells by DNA-PK/AKT/GSK3beta-mediated cyclin D1 overexpression. Oncogene 2010;29:4826-4837.

-31 Vergadi E, Ieronymaki E, Lyroni K, Vaporidi K, Tsatsanis C: Akt Signaling Pathway in Macrophage Activation and M1/M2 Polarization. J Immunol 2017;198:1006-1014.

-32 Zhang Y, Wang L, Zhang M, Jin M, Bai C, Wang X: Potential mechanism of interleukin-8 production from lung cancer cells: an involvement of EGF-EGFR-PI3K-Akt-Erk pathway. J Cell Physiol 2012;227:35-43.

33 Al-Mahrouki AA, Karshafian R, Giles A, Czarnota GJ: Bioeffects of ultrasound-stimulated microbubbles on endothelial cells: gene expression changes associated with radiation enhancement in vitro. Ultrasound Med Biol 2012;38:1958-1969.

-34 El Kaffas A, Nofiele J, Giles A, Cho S, Liu SK, Czarnota GJ: Dll4-notch signalling blockade synergizes combined ultrasound-stimulated microbubble and radiation therapy in human colon cancer xenografts. PLoS One 2014;9:e93888. 